Stefan Pulst, MD, Dr med, FAAN, Massimo Pandolfo, MD, FAAN, Raymond Roos, MD, FAAN, Margherita Milone, MD, PhD and Suman Jayadev, MD

\title{
Neurology: Genetics Year in Review
}

Neurol Genet February 2021 vol. 7 no. 1 e556. doi:10.1212/NXG.0000000000000556

As in the past years, the editors of Neurology ${ }^{\otimes}$ Genetics have chosen articles from our journal and from other publications that we believe deserve highlighting for our readers. The reports cover a variety of mutational mechanisms and diseases as well as novel aspects of clinical phenotypes and neuroimaging.

DNA repeat expansion mutations have revolutionized our understanding of neurologic diseases. A recent addition to this list are expansions in the in replication factor $\mathrm{C}$ subunit 1 (RFC1) and disabled adaptor protein 1 (DAB1) genes. RFC1 mutations act in a recessive fashion and cause cerebellar ataxia, neuropathy, and vestibular areflexia syndrome (CANVAS), whereas DAB1 mutations are dominant and cause SCA37. The Fogel group at University of California at Los Angeles undertook a study to ascertain the prevalence of pathogenic repeat expansions in RFC1 and DAB1 in nearly 1,000 patients from North America with undiagnosed ataxia. Aboud Syriani and colleagues ${ }^{1}$ examined almost 1,000 predominantly adult-onset and sporadic patients that had been excluded for repeat expansions in the SCA2, 3, 6, 7, and Friedreich ataxia genes. Patients were screened for the presence of pathogenic repeat expansions using fluorescent repeat-primed PCR (RP-PCR). In contrast to conventional PCR, RP-PCR is able to amplify large repeats and detect presence of a pathologically expanded repeat, but the precise size of the repeat still needs to be determined by Southern blot analysis. No patients had a DAB1 repeat expansion. Overall, they found that nearly $7 \%$ of patients carried a heterozygous RFC1 expansion. Most patients with typical CANVAS had biallelic RFC1 expansions and many with ataxia and neuropathy, whereas only $2 \%$ of patients with pure cerebellar ataxia and $1 \%$ with a spinocerebellar ataxia phenotype carried biallelic mutations. The study confirmed the importance of screening for RFC1 in ataxia patients, especially in those with a concomitant large fiber neuropathy. Whether heterozygous presence of RFC1 expansion represents a risk allele will require further work.

Transcribed expanded repeats cause several neurodegenerative diseases such as C9orf72associated amyotrophic lateral sclerosis (ALS), spinocerebellar ataxias, Huntington disease, and fragile X ataxia tremor syndrome (FXTAS). Repeat-associated non-AUG-initiated (RAN) translation contributes to the pathogenicity of these repeats by generating toxic peptides. This $s t u d y^{2}$ explored whether there is also a physiologic function for RAN translation of transcribed simple tandem repeats. The authors found a role of RAN translation of normal and FXTASassociated alleles of the FMR1 5'-leader CGG repeat in regulating fragile $\mathrm{X}$ protein (FMRP) synthesis. In human and rodent neurons carrying FXTAS-associated FMR1 5'-leader repeats, CGG RAN-blocking noncleaving antisense oligonucleotides suppressed repeat toxicity, enhanced endogenous FMRP expression, and prolonged survival. However, in neurons, the CGG repeat, even of normal length, and CGG RAN initiation sites are needed for the enhancement of FMRP induced by activation of $m$ GluR5 receptors, delineating a native function for CGG repeats and RAN translation in regulating basal and activity-dependent FMRP synthesis.

The genetic revolution has led to the identification of point mutations that cause a number of inherited diseases. Despite this knowledge, we still have relatively little understanding of
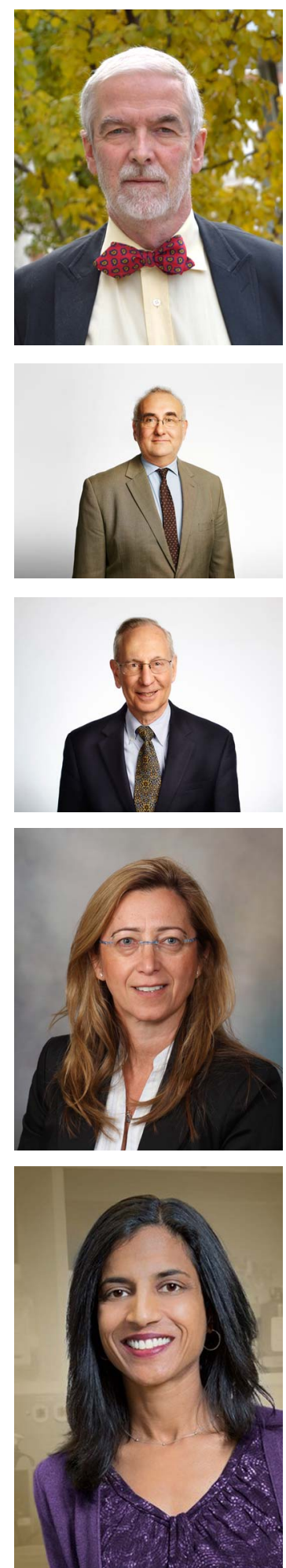

From the Department of Neurology, University of Utah (S.M.P.), Salt Lake City; Université Libre de Bruxelles - Hôpital Erasme (M.P.), Bruxelles, Belgium; University of Chicago Medical Center (R.R.), Chicago, IL; Mayo Clinic (M.M.), Rochester, MN; University of Washington, (S.J.) Seattle, WA. 
additional influences on the development and phenotype of these diseases (age at onset, specific signs, survival, etc.) because of environmental factors and disease-modifying genes. Two publications in Neurology: Genetics by a similar group of authors find an association of disease-modifying structural variants of 2 different genes with inherited ALS. ${ }^{3,4}$ In one case, an association of an insertion/deletion variant within an intron of the sequestosome 1 (SQSTM1) gene was made with familial ALS, especially in patients with SOD1 mutations, but not sporadic ALS. The identification of SQTM1 as a diseasemodifying gene is of interest because mutations in this gene, perhaps related to its role in autophagy, have also been found to be a direct cause of ALS - and other neurodegenerative diseases. The second publication reports that the number of poly-T repeats in the $3^{\prime}$ untranslated region of serine and arginine rich proteins-related carboxy terminal domainassociated factor 4 (SCAF4) modifies disease in a cohort of familial ALS patients, both those with SOD1 mutations and with other gene mutations. The results of these studies, which need to be confirmed, indicate that the noncoding regions of genes may have important influences on disease phenotype and suggests that these regions are therapeutic targets in these diseases.

Chaperones have emerged as a subset of molecules with a crucial role in the organization and maintenance of the sarcomere, the contractile unit of the skeletal muscle. Biallelic pathogenic variants in UNC45B, which encodes a myosinspecific chaperone, were found to cause a progressive myopathy because of impaired myofibrillar organization. ${ }^{5}$ Patients manifested in early childhood with progressive proximal and axial muscle weakness or less frequently in infancy. Most had a variable degree of respiratory insufficiency. Cardiac involvement occurred in the form of electrocardiographic or structural abnormalities. Creatine kinase levels were normal. Muscle biopsies showed internalized nuclei and eccentric unstructured cores; some muscle fibers demonstrated rod-like inclusions and authophagy material. The mutant UNC-45B had reduced expression and mislocalized at the Z-lines. Transgenic expression of the UNC-45 missense variants in $C$. elegans demonstrated impaired myosin binding and muscle function.

X-linked myotubular myopathy, caused by pathogenic variants in MTM1, is the most severe centronuclear myopathy, manifesting with severe hypotonia and respiratory insufficiency in the neonatal period. Despite being an X-linked recessive myopathy, there is a high frequency of manifesting heterozygous women, more than expected for an X-linked disorder. MTM1 female carriers in 2 Brazilian families were investigated for genetic modifiers. ${ }^{6}$ Although the $\mathrm{X}$ chromosome inactivation was random in these subjects, nonmanifesting carriers exhibited at least 3 genetic variants in the killer cell immunoglobulinlike receptor gene cluster on chromosome 19 . The detection of such genetic variants, absent in the female manifesting carriers, suggested a possible protective role of these variants on the development of the muscle disease.
The observation that Alzheimer Disease, a neurodegenerative syndrome, presents in later adulthood has led to the premise that neural dysfunction in the context of aging leads to symptomatic cognitive decline. However, biomarker studies in $\mathrm{AD}$, particularly monogenic $\mathrm{AD}$, remind us that neurodegenerative changes occur decades earlier. Late-onset $\mathrm{AD}$ is also heritable, and genome-wide association study (GWAS) have identified common genetic polymorphisms conferring risk for disease. How and when these risk loci mediate pathogenesis of $\mathrm{AD}$ is a broad question and active area of research. Walhovd et al. ${ }^{7}$ studied the relationship between increased polygenic risk in $\mathrm{AD}$ and structural brain measures decades before the predicted development of neurodegenerative disease. The group analyzed hippocampal volume by brain MRI from 1,181 cognitively normal individuals aged 4-96 years. Using commonly applied risk loci (Lambert et al. ${ }^{8}$ 24162737), a polygenic risk score (PGS) was developed for $\mathrm{AD}$. In addition to adjusting for potential vascular contributions, a PGS for systolic and diastolic blood pressure was developed and used as covariates in their model. The findings demonstrated that AD PGS was associated with smaller hippocampal volume across the age spectrum and not just with older subjects. A trend toward a hippocampal size effect remained even with removal of $A P O E 4$ as a factor. The differences in hippocampal volume between high and low PGS individuals was similar between young and old, underscoring the importance of genetic risk factors in neural physiology. This study suggests that genetic risk for $\mathrm{AD}$ may be manifesting effects earlier in life and that expanding the repertoire of relevant endophenotypes in $\mathrm{AD}$ is likely to boost our understanding of $\mathrm{AD}$ pathogenicity.

Identification of causative gene variants associated with a rare disease can yield pathophysiologic insight into the more common, presumably nonmendelian form of the disease. Cortese et al. ${ }^{9}$ in Nature Genetics (32367058) describe a novel autosomal recessive inborn error of metabolism syndrome caused by biallelic variants in sorbitol dehydrogenase (SORD) leading to distal axonal neuropathy. Axonal Charcot-MarieTooth (CMT), unlike the demyelinating CMTs, frequently escape a genetic diagnosis. Focusing on 598 individuals diagnosed with CMT who had undergone exome or whole genome sequencing, the group identified homozygous or compound heterozygous SORD variants which they suggest represent the most common form of autosomal recessive neuropathy reported. Technical issues with sequencing SORD related to the presence of a homologous pseudogene SORDP2 is potentially one reason why this seemingly significant genetic variant had not been previously reported. The product of $S O R D$ is an enzyme in the sorbitol pathway. Disease variants likely cause a loss of function (LOF). In 10 individuals with homozygous LOF mutations, fibroblast and serum sorbitol levels were elevated. An engineered drosophila loss of function mutation in the fly ortholog Sodh2 results in a neurodegenerative phenotype including synaptic degeneration and locomotor deficiency and elevated sorbitol. Remarkably, aldose reductase inhibitors are now being tried in diabetic neuropathy because of a previously identified association of neuropathy 
with increased sorbitol. The clinically available aldose reductase inhibitors functionally rescued the elevated sorbitol levels and locomotor phenotype in the fly. A pharmacologic intervention for a rare disease with implications for neuropathy caused by a common complex disease is a welcome success.

Cerebral autosomal dominant arteriopathy with subcortical infarcts and leukoencephalopathy (CADASIL) is the most common heritable cause of stroke in before age 65 caused by mutations in the NOTCH3 gene. In addition to strokes, the clinical phenotype of CADASIL includes, migraine, cognitive decline, and psychiatric symptoms. The prevalence, severity, and rate of progression of these symptoms and the underlying pathology are quite variable. An interesting study from Greece $^{10}$ reported a novel NOTCH3 mutation, and the associated clinical and neuroimaging findings and reviewed published NOTCH3 mutation and the associated phenotypes. The study has provided a valuable contribution to our understanding of the variability of clinical manifestations of CADASIL in their severity, timing and progression, and how these differences relate to the underlying mutations.

Handedness is of importance for every clinical neurologist and a fascination for neuroscientists and geneticists owing to its relationship with language and other lateralized functions. Partida and colleagues conducted a GWAS meta-analysis of nearly $1.8 \mathrm{M}$ individuals using data from the UK Biobank, 23andMe, and the International Handedness Consortium. ${ }^{11}$ They identified 41 loci associated with left handedness and 7 with ambidexterity. There were suggestive positive genetic correlations between left handedness and neuropsychiatric traits in agreement with preivous studies that had seen an overrepresentation of left handers in neurodevelopmental disorders. Surprisingly, the genetic correlation between left handedness and ambidexterity was low suggesting that they are largely influenced by nonoverlapping genetic mechanisms. In summary, handedness seems highly polygenic and the left handedness trait shares certain aspects of genetic structure with some psychiatric disorders.

\section{Study Funding}

No targeted funding reported.

\section{Disclosure}

S. Pulst is editor of Neurology: Genetics. M. Pandolfo, R. Roos, M. Milone and S. Jayadev are associate editors for Neurology: Genetics. Go to Neurology.org/NG for full disclosures.

Appendix Authors

\begin{tabular}{lll}
\hline Name & Location & Contribution \\
\hline $\begin{array}{l}\text { Stefan Pulst, MD, } \\
\text { Dr med, FAAN }\end{array}$ & University of Utah & $\begin{array}{l}\text { Drafting/revision of the } \\
\text { manuscript for content }\end{array}$ \\
\hline $\begin{array}{l}\text { Massimo Pandolfo, } \\
\text { MD, FAAN }\end{array}$ & $\begin{array}{l}\text { Université Libre de } \\
\text { Bruxelles }\end{array}$ & $\begin{array}{l}\text { Drafting/revision of the } \\
\text { manuscript for content }\end{array}$ \\
\hline $\begin{array}{l}\text { Raymond Roos, } \\
\text { MD, FAAN }\end{array}$ & $\begin{array}{l}\text { University of Chicago } \\
\text { Medical Center }\end{array}$ & $\begin{array}{l}\text { Drafting/revision of the } \\
\text { manuscript for content }\end{array}$ \\
\hline $\begin{array}{l}\text { Margherita Milone, } \\
\text { MD, PhD }\end{array}$ & Mayo Clinic & $\begin{array}{l}\text { Drafting/revision of the } \\
\text { manuscript for content }\end{array}$ \\
\hline Suman Jayadev, MD & $\begin{array}{l}\text { University of } \\
\text { Washington }\end{array}$ & $\begin{array}{l}\text { Drafting/revision of the } \\
\text { manuscript for content }\end{array}$ \\
\hline
\end{tabular}

\section{References}

1. Syriani DA, Wong D, Andani S, et al. Prevalence of RFC1-mediated spinocerebellar ataxia in a North American ataxia cohort. Neurol Genet 2020;6:e440.

2. Rodriguez CM, Wright SE, Kearse MG, et al. A native function for RAN translation and CGG repeats in regulating fragile X protein synthesis. Nat Neurosci 2020;23: 386-397.

3. Pytte J, Anderton RS, Flynn LL et al. Association of a structural variant within the SQSTM1 gene with amyotrophic lateral sclerosis. Neurol Genet 2020;6:e406.

4. Pytte J, Flynn LL, Anderton RS, et al. Disease-modifying effects of an SCAF4 structural variant in a predominantly SOD1 ALS cohort .Neurol Genet 2020;6:e470.

5. Donkervoort S, Kutzner CE, Hu Y, et al. Pathogenic variants in the myosin chaperone UNC-45B cause progressive myopathy with eccentric cores. Am J Hum Genet 2020; 107:1078-1095.

6. Souza LS, Almeida CF, Yamamoto GL, et al. Manifesting carriers of X-linked myotubular myopathy: genetic modifiers modulating the phenotype. Neurol Genet 2020; 6:e513.

7. Walhovd KB, Fjell AM, Sorensen O. Genetic risk for Alzheimer disease predicts hippocampal volume through the human lifespan. Neurol Genet 2020;6:e506.

8. Lambert JC, Ibrahim-Verbaas CA, Harold D, et al. Meta-analysis of 74,046 individuals identifies 11 new susceptibility loci for Alzheimer's disease. Nat Genet 2013;45: $1452-1458$.

9. Cortese A, Zhu Y, Rebelo AP, et al. Biallelic mutations in SORD cause a common and potentially treatable hereditary neuropathy with implications for diabetes. Nat Genet 2020;52:473-481.

10. Xiromerisiou G, Marogianni C, Dabouli K, et al. Cerebral autosomal dominant arteriopathy with subcortical infarcts and leukoencephalopathy revisited: genotypephenotype correlations of all published cases. Neurol Genet 2020;6:e434.

11. Cuellar-Partida G, Tung JY, Eriksson N, et al. Genome-wide association study identifies 48 common genetic variants associated with handedness. Nat Hum Behav 2021;5:59-70. 


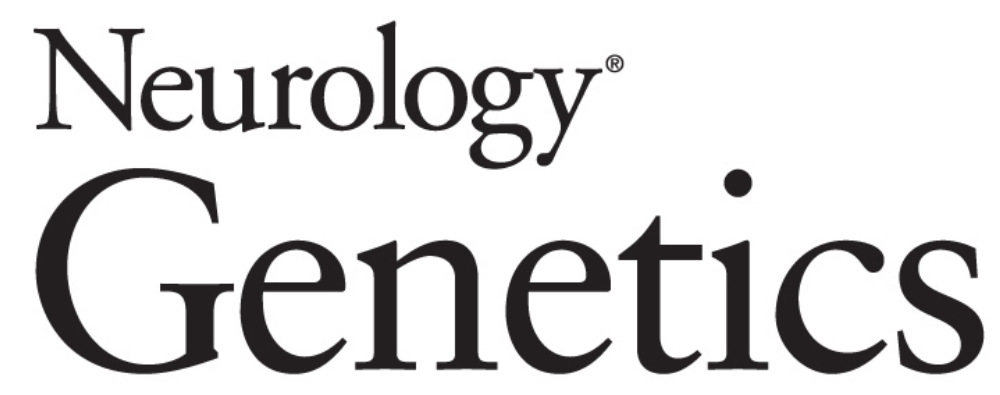

Neurology: Genetics Year in Review

Stefan Pulst, Massimo Pandolfo, Raymond Roos, et al. Neurol Genet 2021;7;

DOI 10.1212/NXG.0000000000000556

This information is current as of February 8, 2021

\section{Updated Information \&} Services

References

Permissions \& Licensing

Reprints including high resolution figures, can be found at: http://ng.neurology.org/content/7/1/e556.full.html

This article cites 11 articles, 7 of which you can access for free at: http://ng.neurology.org/content/7/1/e556.full.html\#\#ref-list-1

Information about reproducing this article in parts (figures,tables) or in its entirety can be found online at:

http://ng.neurology.org/misc/about.xhtml\#permissions

Information about ordering reprints can be found online: http://ng.neurology.org/misc/addir.xhtml\#reprintsus

Neurol Genet is an official journal of the American Academy of Neurology. Published since April 2015, it is an open-access, online-only, continuous publication journal. Copyright Copyright ( 2021 The Author(s). Published by Wolters Kluwer Health, Inc. on behalf of the American Academy of Neurology.. All rights reserved. Online ISSN: 2376-7839.

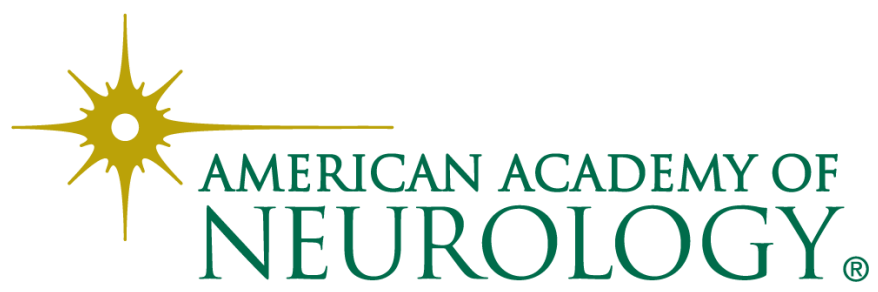

